\title{
ESTUDO DA RELAÇÃO DAS FAMÍLIAS COM O CONTROLE FINANCEIRO DE RECURSOS
}

\author{
families of relationship with the control study of financial \\ resources
}

Recebido: 27/06/2015 - Aprovado: 11/09/2015 - Publicado: 29/12/2015

Processo de Avaliação: Double Blind Review

\author{
Daniel Bassotto ${ }^{1}$ \\ Tecnólogo em Processos Gerenciais \\ Faculdade ENIAC \\ dbassotto@yahoo.com.br \\ Renata Aguiar \\ Tecnóloga em Processos Gerenciais \\ Faculdade ENIAC \\ vendasradistribuidora@hotmail.com \\ Ricardo Camargo de Araújo \\ Mestrado em Administração de Empresas \\ Faculdade ENIAC \\ ricardo.camargo@eniac.com.br
}

RESUMO: Este artigo analisa a realidade enfrentada no controle pessoal e familiar no recebimento, utilização, controle e aplicação de recursos financeiros das pessoas que fazem parte de uma comunidade carente da periferia de São Paulo. A pesquisa foi realizada por meio de questionário respondido pelos membros da comunidade, sendo que os resultados apontam os potenciais e possíveis pontos frágeis a serem desenvolvidos por meio de palestras sobre finanças.

PALAVRA CHAVE: Aplicação Financeira; Controle; Finanças.

ABSTRACT: This article reports the reality faced in personal and family control in the receipt and use, control and application of financial resources of the people who are part of a poor community on the outskirts of the metropolitan region of São Paulo. The research was conducted through a questionnaire answered by community members, and the results show the potential and possible weak points to be developed through talks on finances.

KEYWORD: Financial application; Control; Finance.

\footnotetext{
${ }^{1}$ Autor para correspondência: Faculdade ENIAC - R. Força Pública, 89 - Centro, Guarulhos - SP, Brasil, 07012-030.
} 


\section{INTRODUÇÃO}

O tema foi escolhido para este artigo em função de realizar um estudo sobre uma comunidade religiosa da periferia da Região Metropolitana de São Paulo. Não foi informado o nome, para preservar o sigilo. O artigo aborda como a comunidade realiza o controle financeiro pessoal e familiar.

A comunidade é formada por homens, mulheres, jovens e crianças, o estudo será realizado com as pessoas em fase produtiva profissional, e os aposentados para conhecer o universo em que cada um está inserido bem como sua relação na utilização do dinheiro, para busca de seus sonhos, projetos e o que está fazendo para atingir esses objetivos.

Demonstram-se as opções de aplicação de recursos e relaciona-se com o nível de endividamento dos membros da comunidade.

A justificativa deste estudo é conhecer a realidade enfrentada pela comunidade por meio de pesquisa (questionário) a ser aplicado nas pessoas da comunidade com o objetivo de demonstrar para as pessoas como obter melhor aproveitamento e gerenciamento dos seus recursos financeiros. Esta necessidade surgiu da própria comunidade

Essa temática é atual, uma vez que muitas pessoas não tem conhecimento de como controlar seus recursos financeiros, falta informação e há despreparo no convívio familiar, sendo agravado pela falta de conhecimento acadêmico. Esta realidade tem provocado endividamento nas comunidades, uma vez que não tem ferramentas necessárias para mudar o quadro enfrentado, não conseguindo assim ter uma reserva financeira para solucionar os problemas emergenciais, agravando o quadro dentro do contexto social.

Portanto, a escolha do tema proposto nasce ao perceber as dificuldades que as pessoas da comunidade têm em lidar com questões financeiras. Observa-se que elas fazem questionamentos a respeito disso, sendo que muitas vezes possuem uma quantidade de dinheiro específica, mas não conseguem estabelecer um equilíbrio entre o seus ganhos versus gastos.

Muitas vezes, a falta de informação e despreparo com relação à vida financeira no convívio familiar, agravada pela falta de conhecimento, provoca endividamento nas 
comunidades, uma vez que não tem ferramentas necessárias para mudar o quadro enfrentado. Não conseguindo, assim, ter uma reserva financeira para solucionar os problemas emergenciais, isso faz com que haja uma necessidade de busca de soluções deste quadro no contexto social. Por meio dos resultados obtidos, espera-se criar e oferecer palestras para promover uma ação social para melhor aproveitamento e gerenciamento dos recursos financeiros da comunidade, além de diagnosticar uma realidade que pode ser similar em outras comunidades carentes do país.

Com este artigo busca-se auxiliar no preparo e na apresentação de ferramentas que poderão auxiliar as pessoas e famílias a ter um melhor controle financeiro, além de utilizar de maneira mais adequada o seu dinheiro, planejando o seu orçamento e fazendo um fundo de reserva. Portanto, poupando e trabalhando com provisionamento para atingir seus sonhos, projetos e promovendo um processo de educação financeira para a vida pessoal e familiar, com o objetivo de viverem em uma sociedade melhor, mais responsável, sustentável e com mais qualidade de vida.

Portanto, o objetivo é conhecer a realidade enfrentada pela comunidade sobre a utilização de seus recursos financeiros, sendo que esse estudo foi realizado nesta comunidade, localizada na cidade de São Paulo, que conta com várias famílias de classe média.

Os resultados foram apurados por meio da análise de dados e serão utilizados para palestras, sempre buscando uma maior interação dos membros da comunidade, para que de alguma maneira possam ser melhorar o seu planejamento familiar.

\section{REFERENCIAL TEÓRICO}

\subsection{CONCEITOS INTRODUTÓRIOS}

Muitas pessoas, da região metropolitana de São Paulo, passam por dificuldades em sua vida, devido a razões como falta de estrutura na família, falta de conhecimento, onde a relação com o dinheiro é avaliada ou ainda tratada de uma maneira pouco responsável. Dentro desse universo, as pessoas quando na fase adulta, passam a reproduzir o que viram ou conhecem sobre o dinheiro. Como muitos não tiveram acesso à orientações a respeito disso na infância, adolescência e mesmo na juventude, buscam apenas consumir e isso pode trazer um efeito em cadeia para as próximas gerações que repetem comportamentos. 
Percebe-se que no Brasil nos dias de hoje acontece à situação da inflação, esse fator acaba influenciando a vida das pessoas e das famílias, bem como no poder de consumo pessoal e familiar.

Na visão de Adalgisa (1999, p.18), a população ficou mais pobre devido à inflação, esse empobrecimento acontece não como tempos atrás, mas sim devido a inflação interna do lar, isso vai diminuindo o poder de compra silenciosamente. A autora exemplifica:

um casal tem dois filhos que ingressam na escola, o que implica a compra de tênis, uniformes e pagamento de mensalidade (se trata de uma rede particular de ensino). Só isso acarreta a inflação interna, são gastos que não estavam previstos no orçamento familiar, que é enxuto e todo comprometido. (ADALGISA, 1999, P.18).

Portanto, conclui a autora: "Os gastos com a escola são uma inflação dentro do orçamento familiar, porque o salário não teve aumento, mas a perda do poder de compra vai ocasionar empobrecimento, agravado por dividas e problemas financeiros." (ADALGISA, 1999, P.18).

Eker (2006) destaca:

Vou fazer uma analogia com o projeto de uma casa, que o plano, ou o desenho preestabelecido, para aquela construção. Analogamente, o modelo de dinheiro de uma pessoa é a sua programação, ou o seu modo de ser preestabelecido, com relação às finanças. (EKER, 2006, p. 24).

Nota-se que o desenvolvimento das pessoas tem muita relação com o que foi citado, sendo que Eker (2006) traz algumas problematizações em relação ao modelo financeiro:

\footnotetext{
Vejamos a cultura. Sabemos que algumas sociedades têm formas diferentes de pensar sobre o dinheiro e de lidar com ele, enquanto outras fazem isso de modo diferente. Você acredita que a criança sai do ventre da mãe com as atitudes formadas em relação ao dinheiro ou que ela é ensinada a lidar com ele? Acertou toda criança é ensinada a pensar e agir no que diz respeito às finanças. O mesmo vale para você, para mim e para todas as pessoas. (EKER, 2006, p. 25).
}

Com base nas informações sobre esse possível modelo financeiro, entende-se que as pessoas não sabem utilizar o dinheiro, pois devem obter este aprendizado. Pode- 
se analisar que não é uma tarefa fácil, mas sim, o contato com uma gama de conhecimento, com pessoas e suas experiências, somadas as próprias experiências pessoais. Neste universo pode haver experiências frustradas, pelo fato de serem experiências empíricas, sem o conhecimento e o domínio do assunto tratado sobre o modelo financeiro.

Eker (2006, p. 25) afirma que: "Esses ensinamentos se transformam no condicionamento, que são todas as respostas automáticas que nos conduzem ao longo da vida, a menos, é claro, que sejamos capazes de intervir e rever os arquivos de dinheiro que temos na cabeça." Portanto:

Necessita-se entender o relacionamento com o dinheiro, sabendo-se que existem regras externas e internas, num primeiro momento para utilização do dinheiro, é necessário obter conhecimento comercial, administração financeira, e estratégia de investimento. (EKER, 2006, p.17).

Percebendo-se que a inflação interna, ou seja, o jogo interno, é fundamental para se entender o contexto da utilização dos recursos obtidos.

Eker (2006) analisa:

Vou fazer uma analogia com um carpinteiro e as suas ferramentas. Ter as mais modernas ferramentas é indispensável para ele, porém ser um carpinteiro de primeira categoria, capaz de utilizá-las com a habilidade de um mestre, é ainda mais importante. Eu sempre digo: não basta estar no lugar certo na hora certa. Você tem que ser a pessoa certa, no lugar certo, na hora certa. (EKER, 2006, p.17).

Com base nas informações sobre o conhecimento comercial, administração financeira e estratégia de investimento entende-se que não basta apenas obter recursos, mas sim, ter a clareza do que fazer e como fazer para que se obtenha êxito por meio de ferramentas adequadas e habilidade a fim de viver os resultados que o dinheiro pode trazer a quem utilizá-lo com parcimônia, ou seja, com moderação, sabendo aproveitar as oportunidades que surgem ao longo da vida. A partir dessas reflexões, entende-se que há uma necessidade de conhecer-se.

Eker (2006) menciona alguns questionamentos necessários para isso:

Quem é você então? Como você pensa? Quais são as suas crenças?

Quais são os seus hábitos e as suas características? Qual é a sua opinião sobre si mesmo? Quanta confiança você tem em si mesmo? Como é o seu relacionamento com as pessoas? Até que ponto você confia nelas? Você realmente acredita que merece ser rico? Qual é a sua capacidade de agir 
apesar do medo, da preocupação, do incõmodo, do desconforto? Você consegue seguir em frente mesmo quando não está disposto a fazer isso? (EKER, 2006, p. 17).

\subsection{IMPACTOS NA FAMÍLIA COM A FALTA DE DINHEIRO}

Kiyosaki (2001) afirma que a melhor maneira de ensinar sobre a relação do consumo de bens, produtos e serviços é falar de forma aberta sobre o que está acontecendo. Essa postura pode esclarecer os fatos e deixar as pessoas envolvidas cientes da situação real a ser enfrentada, além de mostrar a realidade da família e as decisões que precisaram ser tomadas.

Kiyosaki (2001, p. 53-54) relata:

$\mathrm{Na}$ quinta feira à noite, perguntei se poderíamos comprar uma casa de praia perto da casa de Richie. Foi, então, que meu pai explodiu. Havia ouvido o bastante. De que você pensa que sou feito...de dinheiro? não temos uma casa na praia porque não temos condições de ter. Mal consigo pagar as contas e colocar comida na mesa. Canso-me de trabalhar o dia inteiro, venho para casa e vejo contas que não consigo pagar e agora você quer que eu compre uma casa de praia.

Nota-se, que os conflitos em meio a uma crise financeira podem afligir a família, devido ao fato dos problemas financeiros. Os mesmos precisam ser conversados e esclarecidos, principalmente a fim de que os cônjuges e filhos estejam cientes e aprendam, a fim de não cometerem as mesmas falhas na vida financeira.

Conforme Adalgisa (1999, p.13): “O devedor dos dias de hoje é uma pessoa comum, que deu um passo maior que a pernas. Deve sim, mas não ficou devendo por má fé. Ele faz a divida tendo a convicção, naquele momento, que não vai poder pagála.". A autora afirma, ainda:

Com a inflação doméstica, as pessoas, mesmo sem fazer novas dividas, começam a ficar um pouco endividadas. Apesar de não comprarem nada, de não fazerem novos crediários, de não entrarem no cheque especial, as pessoas contraem pequenas dívidas porque o orçamento não cobre as despesas do mês. Isso está virando uma rotina nas famílias brasileiras. Tem início a rodaviva dos gastos porque não entra dinheiro suficiente para o pagamento das dívidas assumidas. (ADALGISA, 1999, p. 19).

Kiyosaki (2001, p. 54) afirma no exemplo a seguir:

REMIPE- Revista de Micro e Pequenas Empresas e Empreendedorismo da Fatec Osasco 
Mais tarde, naquela mesma noite, minha mãe foi a meu quarto e silenciosamente fechou a porta atrás de si, Trazia vários envelopes. Sentandose a meu lado na cama, disse: — Seu pai está sob enorme pressão financeira. Fiquei ali naquele quarto escuro, em meio a um turbilhão de emoções, olhando para minha mãe. Por ter nove anos de idade, estava triste, chateado, com raiva e decepcionado.

Entende-se que um fator importante a ser considerado é o de promover reuniões mensais em família, com o objetivo de falar sobre o planejamento financeiro, e caso necessário, mudar os hábitos de consumo utilizando novos critérios para o estabelecimento das prioridades para os próximos meses, desta forma a família aprende a conquistar e cada membro cresce e atinge seus objetivos pessoais e coletivos.

Luquet (2012, p. 30) ensina que: “A melhor forma de fazer suas escolhas é pensar sobre suas metas e estratégias para alcançar seus sonhos. Assim, sempre que você tiver prestes a gastar demais vai lembrar que está ficando mais longe de conquistar seus objetivos."

Aprende-se que uma boa gestão dos recursos financeiros trará maior liberdade para a tomada de decisão para novos investimentos e aumento de patrimônio, esse processo acontece em longo prazo, aprendendo sempre a investir e ter estabilidade financeira, (LUQUET, 2012, p. 192) "O segundo do dinheiro" apud Boff, diz que: "é aquele para economizar". Trata-se de uma reserva preventiva entendendo que a vida da muitas voltas, podendo ocorrer situações como desemprego, aposentadoria insuficiente, por isso a importância de medirem-se as decisões e as sobras de dinheiro o que fazer, guardar no colchão ou aplicá-lo para aumentar a produção do recurso acumulado, para utilizá-lo em sonhos e projetos no futuro.

Mas afinal é possível sair das dividas, (LUQUET, 2012, p. 70) traz uma reflexão interessante, que mostra: Você enriquece quando seu patrimônio líquido aumenta dia após dia, ano após ano.

Na visão de Luquet (2012, p.70) esclarece que:

E o patrimônio líquido é aquele número que aparece quando você subtrai o que deve (cheque especial, cartão de crédito, financiamentos, etc.) daquilo que tem (aplicações, imóveis, dinheiro em conta corrente, por exemplo). O patrimônio líquido é um quadro mais completo da situação financeira do que o salário. Ele pode revelar um cenário sombrio do impacto dos financiamentos na saúde financeira. De que adianta ganhar mais se as dívidas crescem? Aliás, este é um ponto relevante. Muitas vezes uma promoção pode 
ser uma armadilha. O que deveria ser um meio de viver melhor acaba gerando uma guilhotina financeira. Você vira refém do seu emprego.

Aprende-se que para sair das dívidas não é um processo fácil, para isso deve-se escolher como atravessar esse processo, Luquet (2012 p.73) traz uma visão interessante. Afirma que, caso aconteça de uma pessoa ficar em uma situação de insolvência e não ter como pagar as dívidas, a melhor solução é procurar uma nova maneira para se reerguer, ou seja, nesse momento as dividas serão seu melhor investimento para o processo de mudança. Isso vai implicar em trocar as dívidas caras por dívidas de menor valor para consolidação das dividas contraídas. Pode ainda optar por pagar separadamente (uma a uma), com paciência. Pagar as dívidas pode proporcionar muito mais do lucro financeiro e obter aprendizado.

Luquet (2012) relata três soluções para reestruturar as dívidas, a saber:

1- Conhecer todas as dívidas e o custo de cada uma delas. Depois fazer um ranking, das mais caras para as mais baratas.

2- Separe até $30 \%$ de seu orçamento para quitar as dívidas.

3- O melhor é procurar auxilio profissional.

Mas, destaca que uma alternativa é procurar o PROCON ou a defensoria de seu estado, pois os governos têm assistência jurídica gratuita a quem não pode pagar advogado.

\section{METODOLOGIA}

\subsection{DESENVOLVIMENTO}

Este artigo pautou-se na abordagem quantitativa, visando-se conhecer estatisticamente os dados financeiros da comunidade pesquisada na utilização e controle dos recursos financeiros.

Mascarenhas (2012) afirma que:

Como o próprio nome indica, a pesquisa quantitativa baseia-se na quantificação para coletar e, mais tarde, tratar os dados obtidos. Nesse tipo de pesquisa, é fundamental usar técnicas estatísticas, como porcentagens, médias e desvio padrão, por exemplo - tudo isso para tornar o estudo mais imparcial, evitando assim a influência do pesquisador sobre os resultados. (MASCARENHAS, 2012, p. 45). 
Entende-se que fatores importantes da pesquisa quantitativa é a confiabilidade e generalização às mesmas são partes importantes da pesquisa (MASCARENHAS, 2012, p. 45):

Acredita-se que estudos baseados em dados quantitativos ofereçam uma base mais segura para o pesquisador tire suas conclusões. [...] com uma mãozinha da estatística dá para analisar uma grande quantidade de dados o que permite generalizar os resultados da pesquisa.

Observa-se que existem vários tipos de estudos quantitativos, conforme afirma Mascarenhas (2012, p.45), sendo que considera como mais comuns:

- Estudos de correlação de variáveis - verificam- se há uma relação entre variáveis. [...]

- Estudos comparativos causais - objetivo é encontrar a causa de um fenômeno.

Para realizar a análise dos dados é relevante escolher a maneira que os mesmos serão utilizados conforme a coleta dos dados, análise dos conteúdos, discursos e métodos utilizando-se a hermenêutica.

Para complementação sobre esse tema, destaca-se Flick (2009, p.21), que aborda sobre a coleta de dados e a interpretação da pesquisa quantitativa:

Os princípios norteadores das pesquisas quantitativas baseiam-se em "isolar claramente causa e efeito, operacionalizar adequadamente relações teóricas, medir e quantificar fenômenos, desenvolver plano de pesquisa que permitam a generalização das descobertas e formular leis gerais."

Utilizou-se como instrumento de pesquisa um questionário para conhecer quantitativamente a utilização e controle dos recursos financeiros.

Na visão de Mascarenhas (2012, p. 70) é importante entender que:

Seja como for a aplicação, o pesquisador deve, sempre que possível orientar o participante a não escrever seu nome. $O$ anonimato pode deixa-lo confortável para revelar o que realmente pensa sobre o assunto. $\mathrm{O}$ questionário também facilita a tabulação e a análise dos dados como um todo. Outra vantagem é a objetividade na coleta: ao contrário da entrevista, o questionário não exige uma participação ativa do pesquisador, o que ajuda a reduzir sua influência sobre os resultados.

\section{RESULTADOS DA PESQUISA}

REMIPE- Revista de Micro e Pequenas Empresas e Empreendedorismo da Fatec Osasco 
A seguir apresenta-se os resultados da pesquisa, conforme os questionários aplicados na comunidade.

As tabelas apresentadas são as seguintes:

Tabela 1 - Perfil dos pesquisados.

Tabela 2 - Nível de renda individual e familiar.

Tabela 3 - Nível de endividamento.

Tabela 4 - Controle das finanças e aplicação de recursos. 
Tabela 1 - Perfil dos pesquisados

\begin{tabular}{|c|c|c|}
\hline & & Total \\
\hline \multirow{9}{*}{ Idade } & $0-17$ & $\mathrm{O}$ \\
\hline & $18-25$ & 1 \\
\hline & $26-33$ & 3 \\
\hline & $34-42$ & 7 \\
\hline & $43-51$ & 5 \\
\hline & $52-60$ & 3 \\
\hline & $61-69$ & $\mathrm{O}$ \\
\hline & $70-78$ & 1 \\
\hline & Acima de 79 & 2 \\
\hline \multirow{2}{*}{$\operatorname{sexo}$} & Masculino & 9 \\
\hline & Feminino & 13 \\
\hline \multirow[t]{5}{*}{ Estado civil } & Solteiro & 7 \\
\hline & Casado & 13 \\
\hline & Separado & $\mathrm{O}$ \\
\hline & Divorciado & $\mathrm{O}$ \\
\hline & Viuvo & 1 \\
\hline \multirow{12}{*}{ Nível de Escolaridade } & Fundamental & $\mathrm{O}$ \\
\hline & Completo & 4 \\
\hline & Incompleto & 3 \\
\hline & Ensino médio & 1 \\
\hline & Completo & 1 \\
\hline & Incompleto & 4 \\
\hline & Superior & 1 \\
\hline & Completo & 3 \\
\hline & Incompleto & 2 \\
\hline & Pós graduação & $\mathrm{O}$ \\
\hline & Completo & 3 \\
\hline & Incompleto & 2 \\
\hline \multirow[t]{6}{*}{ Atividade profissional } & Empresário & 7 \\
\hline & Autônomo & 2 \\
\hline & Profissional liberal & 5 \\
\hline & Público & 1 \\
\hline & Privado & 9 \\
\hline & Aposentado & 3 \\
\hline
\end{tabular}

Fonte: Dados da Pesquisa. 
Conforme a tabela 1, verificou-se que há uma concentração de 7 (sete) pessoas na faixa etária entre 34 e 42 anos (trinta e quatro e quarenta e dois anos) e 5 (cinco) pessoas na faixa etária entre 43 e 51 anos (quarenta e três e cinquenta e um anos).

Percebeu-se entre os pesquisados que 13 (treze) pessoas são do sexo feminino e 9 (nove) pessoas do sexo masculino. A pesquisa aponta que as mulheres estão exercendo atividades remuneradas e são maioria na pesquisa da comunidade.

Das pessoas pesquisadas 7 (sete ) são solteiras gerando renda para suas necessidades e 13 (treze) são casadas, gerando receita para si e para a renda da família.

Os dados coletados nos mostram o nível de escolaridade: 3 (três) pessoas com nível superior completo, 3 (três) pessoas com pós -graduação completa e 2 (duas) pessoas com pós- graduação incompleta.

Com relação às atividades profissionais remuneradas os seguintes dados foram detectados 7 (sete) pessoas são empresários, 2 (dois) são autônomos, 5 (cinco) atuam como profissionais liberais, sendo que 1 (uma) das pessoas desenvolve suas atividades profissionais no setor público e 9 (nove) atuam no setor privado, notou-se que 3 (três) entre os pesquisados são aposentados.

A pesquisa mostra que atualmente 7 (sete) pessoas estão estudando, 2 (dois) em escola pública e 7 em escolas particulares, com uma mensalidade em torno de até 1 salário mínimo vigente no valor de $\mathrm{R} \$ 724,00$ (setecentos e vinte e quatro reais).

Tabela 2 - Nível de renda individual e familiar

\begin{tabular}{|l|l|r|}
\hline \multirow{4}{*}{ Renda individual atual } & Até 1 salário mínimo & 2 \\
\cline { 2 - 3 } & De 2 a 5 salários mínimos & 12 \\
\cline { 2 - 3 } & De 5 a 9 sal. mínimos & 1 \\
\cline { 2 - 3 } Renda familiar atual & Acima 10 sal. mínimos & 3 \\
\hline \multirow{3}{*}{} & Até 1 salário mínimo & 0 \\
\cline { 2 - 3 } & De 2 a 5 sal. mínimos & 10 \\
\cline { 2 - 3 } & De 5 a 9 sal. mínimos \\
\cline { 2 - 3 } & Acima 10 sal. mínimos & 2 \\
\hline
\end{tabular}

Fonte: Dados da Pesquisa.

Ao analisar a tabela 2, observa-se que os indivíduos com atividade remunerada informaram que, a renda mensal individual atual está em torno de 2 (dois) a 5 (cinco) salários mínimos, enquanto a renda familiar de $10(\mathrm{dez})$ dos pesquisados está em torno 
de 2 (dois) a 5 (cinco) salários mínimos, verificou-se ainda que 7 (sete) dos pesquisados contam atualmente com uma renda familiar entre 5 (cinco) a 9 (nove) salários mínimos.

Tabela 3 - Nível de endividamento

\begin{tabular}{|l|l|r|}
\hline \multirow{2}{*}{ Dívidas } & Sim & 16 \\
\cline { 2 - 3 } & Não & 4 \\
\hline \multirow{3}{*}{ Endividamento } & Até $50 \%$ da renda mensal & 6 \\
\cline { 2 - 3 } & Até $100 \%$ da renda mensal & 0 \\
\cline { 2 - 3 } & Acima de $100 \%$ ren mensal & 0 \\
\hline
\end{tabular}

Fonte: Dados da Pesquisa.

A tabela 3 apresente o nível de comprometimento de renda em compras a prazo e o nível de endividamento da comunidade. Demonstra que 16 (dezesseis) pessoas realizam suas compras a prazo e estão conseguindo honrar os compromissos assumidos, por outro lado, 4 (quatro) pessoas estão endividadas acima de seus recebimentos mensais. A pesquisa mostra, ainda, que 6 (seis) pessoas tem um comprometimento de renda de $50 \%$ dos seus recebimentos mensais.

Tabela 4 - Controle das finanças e aplicação de recursos

\begin{tabular}{|l|l|r|} 
Controle das finanças & Sim & 12 \\
\cline { 2 - 3 } & Não & 9 \\
\hline \multirow{3}{*}{ Tipo de controle } & Planilha & 5 \\
\cline { 2 - 3 } & Agenda & 5 \\
\cline { 2 - 3 } & da internet & 0 \\
\hline \multirow{2}{*}{ Aplicação de recursos } & Sim & 3 \\
\cline { 2 - 3 } & Não & 18 \\
\hline
\end{tabular}

Fonte: Dados da Pesquisa.

Percebeu-se que 12 (doze) indivíduos da pesquisa informaram que realizam algum tipo de controle dos recursos financeiros, sendo que 5 (cinco) realizam seus controles por meio de planilhas e 5 (cinco) utilizam-se de agendas pessoais, porém 9 (nove) dos pesquisados não realizam qualquer tipo de controle de suas receitas e despesas. 


\section{CONCLUSÃO}

Este estudo teve como objetivo mostrar as opções, os recursos existentes para melhor administrar a saúde financeira familiar, bens, aplicações de recursos de uma comunidade pesquisada.

A metodologia utilizada se realizou sob a abordagem quantitativa. Os dados foram coletados por meio do instrumento de pesquisa (questionário) e permitiram conhecer a realidade enfrentada pela comunidade.

Percebeu-se que as pessoas não têm um controle mensal da utilização dos recursos financeiros, esse fato aponta para a necessidade de um trabalho mais aprimorado para proporcionar ajustes e correções de situações de descontrole, para esclarecimento e aprimoramento de detalhes que são de extrema relevância na vida financeira dos pesquisados, por meio do conhecimento e controle das finanças os mesmos poderão passar a usufruir de uma vida melhor com consciência da realidade na qual estão inseridos.

Com base nos resultados obtidos e análise dos mesmos, nota-se a necessidade de elaboração de palestras e atividades junto à comunidade, no sentido de trazer uma maior consciência sobre recebimento e controle dos recursos recebidos, com o objetivo de melhorar suas finanças e trazer maior estabilidade para a vida pessoal e familiar. Os resultados encontrados possibilitam a realização de estudos que podem indicar a melhor utilização dos recursos, fazendo com que sua aplicação gere benefícios futuros e realização de sonhos e projetos com conhecimento e clareza.

A busca de melhores condições de trabalho e renda, bem como a utilização de ferramentas para o desenvolvimento pessoal, favorece o equilíbrio financeiro e a satisfação pessoal e familiar.

\section{REFERÊNCIAS}

ADALGISA, Flávia. O devedor: a luta para vencer a guerra das dívidas. São Paulo: JSN Editora, 1999.

EKER. T. Harv. Os segredos da mente milionária. Rio de Janeiro: Sextante, 2006.

KIYOSAKI, Robert T. O guia do pai rico: filho rico, filho vencedor: como preparar seu filho para ganhar dinheiro. Rio de Janeiro: Campus, 2001. 
LUQUET, Mara. O meu guia de finanças pessoais: como gastar sem culpa e investir sem erros. Rio de Janeiro: Elsevier; São Paulo: Letras \& Lucros, 2012.

MASCARENHAS, Sidnei Augusto. Metodologia científica. São Paulo: Pearson Education do Brasil, 2012. 